www.volsu.ru

DOI: http://doi.org/10.15688/nav.jvolsu.2018.1.8

UDC 930.26(470.44):903.2

LBC 63.48(235.4)-41

\title{
METALWARE AND POTTERY FROM THE HMELEVKA I SETTLEMENT
}

\author{
Leonard F. Nedashkovsky \\ Kazan (Volga region) Federal University, Kazan, Russian Federation
}

\author{
Marat B. Shigapov \\ Institute of Archaeology named after A.Kh. Khalikov, Academy of Sciences of the Republic of Tatarstan, \\ Kazan, Russian Federation
}

\begin{abstract}
The paper deals with the objects of armament, horse equipment and daily life from the Hmelevka I settlement of the second half of $13^{\text {th }}-14^{\text {th }} \mathrm{cc}$. The settlement is located in the Saratov Volga region and was studied by expedition of Kazan University headed by L.F. Nedashkovsky in 1995-2002. The armament is represented by fragments of axes, arrowheads and ceramic bomb; the horse equipment - by the iron framework of supporting buckle, ring from bridle, horseshoe and debacle thorns. Rivets, fragments of copper and bronze vessels, sheets, cast-iron cauldrons, iron plough blade, scythe, knives and their couplings, locks and keys make the daily life objects analyzed in the paper. We provide the data on the mass material, including ceramics (spindle-whorls, unglazed Golden Horde, Old Russian, Mordvin pottery, fragments of Trebizond amphorae, stamped vessels and fragments of glazed red-clay and kashi vessels). The broad comparative background of materials of synchronous monuments of Eastern Europe and Asia is used as a basis for studying the morphological features of metalware and pottery and to make typology. The Hmelevka I settlement can be characterized as urban site, as well as larger Uvek site, but the shown differences in material culture reflect differences in the daily life and culture of the population of the town and the city of Golden Horde, respectively. City dwellers (especially the sedentary Golden Horde aristocracy, who lived predominantly in the cities) were apparently more connected with military affairs and trade, and the population of town - with subsidiary farming and cattle breeding.

Key words: settlements, the Golden Horde, the Lower Volga region, regions of the Uvek site, armament, horse equipment, objects of daily life, pottery, material culture.
\end{abstract}

Citation. Nedashkovsky L.F., Shigapov M.B., 2018. Metalware and Pottery from the Hmelevka I Settlement. The Lower Volga Archaelogical Bulltin, vol. 17, no. 1, pp. 160-176. (in Russian).

УДК 930.26(470.44):903.2

ББК 63.48(235.4)-41

\section{МЕТАЛЛИЧЕСКИЕ ИЗДЕЛИЯ И КЕРАМИКА С ХМЕЛЕВСКОГО І СЕЛИЩА}

Леонард Федорович Недашковский

Казанский (Приволжский) федеральный университет, г. Казань, Российская Федерация

\section{Марат Баязитович Шигапов}

Институт археологии им. А.Х. Халикова Академии наук Республики Татарстан, г. Казань, Российская Федерация

Аннотация. В статье рассматриваются предметы вооружения, конского снаряжения и быта с Хмелевского I селища второй половины XIII - XIV в., располагающегося в Саратовском Поволжье и изучавшегося в 1995-2002 гг. экспедицией Казанского университета под руководством Л.Ф. Недашковского. Вооружение представлено фрагментами топоров, наконечниками стрел и фрагментом керамической бомбы. Конское снаряжение - железными рамкой подпружной пряжки, кольцом от узды, подковой и ледоходными шипами. Из предметов быта в статье привлечены заклепки, фрагменты медных и бронзовых сосудов, листов, чугун- 
ных котлов, железные чересло, коса, ножи и их муфты, замки и ключи. Приводятся данные о массовом материале, в том числе о керамических изделиях, представленных напряслами, неполивной золотоордынской, древнерусской, мордовской посудой, фрагментами трапезундских амфор, штампованных сосудов и фрагментами поливных красноглиняных и кашинных сосудов. Для изучения морфологических особенностей изделий из металла и керамики и составления типологии в статье привлечен широкий сравнительный фон материалов синхронных памятников Восточной Европы и Азии. Хмелевское I селище можно характеризовать как памятник городского типа, как и более крупное по размерам Увекское городище, однако приведенные различия в материальной культуре отражают отличия быта и культуры населения малого и крупного золотоордынского города соответственно. Жители крупного города (особенно оседлая золотоордынская аристократия, проживавшая преимущественно в городах), очевидно, в большей степени были связаны с военным делом и торговлей, а население малого города - с подсобными земледелием и скотоводством.

Ключевые слова: поселения, Золотая Орда, Нижнее Поволжье, округа Увекского городища, вооружение, конское снаряжение, предметы быта, керамика, материальная культура.

Цитирование. Недашковский Л. Ф., Шигапов М. Б., 2018. Металлические изделия и керамика с Хмелевского I селища // Нижневолжский археологический вестник. Т. 17, № 1. С. 160-176.

Ближайшими к Увекскому городищу, на месте которого находился крупный золотоордынский город Укек, остатками малого городского поселения эпохи Улуса Джучи является Хмелевское I селище. Селище датируется второй половиной XIII - XIV в., на нем найдены нумизматические материалы начала 70 -х гг. XIII - конца XIV в.

Научное исследование селища осуществлялось экспедицией Казанского университета 1995-2002 гг. (1995-1998 и 2002 гг. - разведки, 1999-2001 гг. - раскопки), возглавлявшейся Л.Ф. Недашковским.

В статье рассматриваются предметы вооружения, конского снаряжения и быта. Данный комплекс характеризует материальную культуру малого золотоордынского города Нижнего Поволжья, которая, судя по приводимым находкам, отличалась от материальной культуры расположенного неподалеку крупного города Укека.

\section{Предметы вооружения}

Tonopbl. Имеются два фрагмента топоров (рис. 1,1-2). Судя по имеющемуся фрагменту обуха (рис. 1,1), он принадлежал топору без щековиц, выделенных цапф и выступающего обушка. Данный фрагмент откован из заготовки пакетного металла - полос кричного железа и неравномерно науглероженной сырцовой стали [Недашковский, Семыкин, 2014, с. 36]; он происходит из ямы 2 , в которой был найден сарайский пул Узбека 737 г.х. [Недашковский, 2011, c. 43-44]. Этот тип топора может считаться уни- версальным, подобные топоры датируются XII$\mathrm{XV}$ вв. [Кирпичников, 1966, с. 29-30, 40, рис. 6 ,VIIIA, 29,8-9, 30,12, табл. XV,8-9, $\mathrm{XVI}, 12]$. Такие находки известны с Увекского [Недашковский, 2000, с. 70-72, рис. 13,5-6] и Водянского городищ, они характерны для памятников Восточной Европы X-XIV вв. [Савченкова, 1996, с. 14, 16, рис. 2,9]. На фрагменте лезвия топора (рис. 1,2) прослежена схема трехслойного пакета с вваркой углеродистой стальной лезы в основу из менее науглероженной стали [Недашковский, Семыкин, 2014, с. 36].

Наконечники стрел. Представлены два типа.

Тип 1. «Срезни» (3 экз.) в виде вытянутой лопаточки с линзовидным в сечении пером (рис. 1,4-6). Исследованный металлографически наконечник (рис. 1,6) откован из цельностальной заготовки [Недашковский, Семыкин, 2014 , с. 36]; другой наконечник из раскопа (рис. 1,5 ) найден в яме 2 [Недашковский, 2011, с. 4344]. Подобные наконечники стрел широко бытовали в Восточной Европе и Центральной Азии в XIII-XIV вв. [Казаков, 1991, с. 94, 96, рис. 34,18 ; Медведев, 1959 , с. 163,167 , тип 19 , рис. $13,32,15,9 ; 1966 \mathrm{a}$, с. $75-76$, тип 67 , табл. $24,2-6,26,27-31,30,64-65 ; 19666$, с. 5356 , тип 2, рис. $1,1-2,2,2-9,3,1,4,5,7$; Недашковский, 2000, с. 74; Руденко, 2011, с. 127, рис. 8; Савченкова, 1996, с. 72, 75-76, рис. 33,11-13; Федоров-Давыдов, 1966, с. 26, 28, 116, рис. $3,9, B L X, B X I$.

Тип 2. Четырехгранный бронебойный наконечник, ромбический в сечении, с круглой шейкой (рис. 1,3$)$, откован из неравномерно на- 
углероженной сырцовой стали [Недашковский, Семыкин, 2014, с. 36]. Такие наконечники известны с древнерусских и булгарских памятников XI - первой половины XIII в., а также встречаются в материалах Болгарского городища XIV в. [Медведев, 1959, с. 170, тип 11, рис. 13,$50 ; 1966$ a, с. 82 , тип 85 , табл. $19,24,21,24$, 25,4, 12, 30,84; Савченкова, 1996, с. 72-73, 77, рис. 33,21$]$.

Фрагмент керамической бомбы, толстостенного полого шара диаметром $14 \mathrm{~cm}$ коричневого цвета со сквозными отверстиями в стенках, с примесью песка в тесте, оплавленного изнутри (рис. 1,9). Такие шары известны с Увекского, Водянского, Селитренного и Маджарского городищ [Недашковский, 2000 , с. $76,78,80$, рис. $17,9,18,1,3 ; 2010$ a, с. 174 , рис. 11], найдены в Азове [Волков, 1992, с. $6-$ 7, 20, табл. 1,B6], Сарайчике, на городище Актобе и в Казанском Кремле.

\section{Конское снаряжение}

Имеется прямоугольная в сечении рамка железной пряжки (рис. 1,7), использовавшейся для крепления подпруги. Аналогичные пряжки встречаются на памятниках Древней Руси XII-XIII вв. [Кирпичников, 1973, с. 77, рис. 43,5], Среднего Поволжья IX-XIV вв. [Казаков, 1991, с. 104,107 , рис. 36,10$]$ и средневековых кочевников Восточной Европы [Федоров-Давыдов, 1966, с. 43, 46, рис. 7,3,АII].

Железное кольио (рис. 1,8) от узды, изготовлено из неравномерно науглероженной сырцовой стали [Недашковский, Семыкин, 2014, c. 37]. Подобные кольца известны на средневековых памятниках Среднего Поволжья XXIV вв. [Казаков, 1991, с. 104, рис. 36,1-5].

Подкова (рис. 2,1) из квадратного дрота изготовлена из неравномерно науглероженной сырцовой стали [Недашковский, Семыкин, 2014, с. 37]. Имеет аналогии в материалах Лаишевского селища, Увекского [Недашковский, 2000, с. 77, 79, рис. 16,1-3], Селитренного [Fyodorov-Davydov, 1984, fig. 96,15], Болгарского [Савченкова, 1996, с. 63-66, рис. 29,18 ], Водянского городищ и Отрара; такие изделия датируются XIII-XV вв.

Ледоходные шипы (2 экз.). Размеры лучше сохранившегося изделия (рис. 2,2) $3,9 \times 2,6$ см. Еще один шип происходит из подъемного материала 2002 г. Сходные ледоходные шипы широко использовались в Восточной Европе в XI-XV вв.; они имеют аналогии на Увекском городище, в урочище Подстепное [Недашковский, 2000, с. 77-79, рис. 16,4, 17,5-7], на Болгарском городище [Савченкова, 1996, с. 65-66, рис. 30] и Лаишевском селище [Руденко, 2011, с. 131, рис. 12,6].

Предметы быта представлены заклепками и фрагментами сосудов (литых бронзовых и чугунных, кованых медных), череслом, косой, ножами, муфтами, замками и ключами.

Заклепки металлических сосудов представлены тремя экземплярами, изготовленными сворачиванием листа в конус (рис. 2,3-5). Одна из заклепок не была применена (рис. 2,3), еще 2 - сплющены и деформированы (рис. 2,45), что говорит об их использовании. Две заклепки изготовлены из «чистой» меди, третья из оловянистой бронзы [Недашковский, 2002, c. 337-338, 343-344, № 109-111]. Заклепки таких форм применялись для крепления ушек тазов; они хорошо известны с памятников Среднего и Нижнего Поволжья [Недашковский, 2000, с. $81-82$, рис. $19,1-9]$.

Фрагменты литых сосудов представляют собой обломки стенки (рис. 2,13) и венчика (рис. 2,16 ) чаш. Они отлиты из оловянистой бронзы [Недашковский, 2002, с. 337-338, 343, № 107-108].

Фрагменты кованых сосудов представлены 17 экземплярами (рис. 2,8-9,11,14,17,2223,26 ), очевидно, обломками котлов, включая фрагмент венчика с остатками железного ушка (рис. 2,11); не приведенные на иллюстрациях фрагменты являются подъемным материалом 1999 г. Обломки листов (рис. 2,6-7, 10, 12,15,1821,24-25), вероятно, также принадлежат к числу фрагментов сосудов. Из 15 фрагментов кованых сосудов и листов, подвергнутых анализу, 7 были изготовлены из «чистой» меди, 6 - из свинцово-оловянистых бронз, а 2 - из оловянистых бронз [Недашковский, 2002, с. 337-338, 342345, № 85-88, 93-95, 97, 112-116, 141; 2010б, c. $148-149,151$, № 176].

Фрагменты чугунных котлов имеют разную толщину (рис. 3,1-6). Аналогичные котлы представлены на памятниках Золотой Орды и сопредельных территорий [Недашковский, 2000, с. 84-86, рис. 20,2-5]. 
Железное чересло (рис. 3,7) отковано с применением технологии вварки стальной полосы в основу из кричного железа [Недашковский, Семыкин, 2014, с. 39]. Изделие сходно по форме и размерам орудиям XII-XIV вв., найденным на Болгарском городище [Савченкова, 1996, с. 9-10, рис. 1,4-6]. Находки на селищах Среднего Поволжья X-XIV вв. [Казаков, 1991 , с. $58-60,64$, рис. $20,5,21]$ по размерам значительно меньше.

В яме 4, датируемой монетами 30-х начала 50-х гг. XIV в., найден фрагмент железной косы (рис. 4,3), изготовленной из кричного железа [Недашковский, 2011, с. 44; Недашковский, Семыкин, 2014, с. 37, ан. 1000]. Длина сохранившейся части изделия $-9,2$ см, а ширина $-3,2$ см.

Муфты ножей (рис. 4,1) представлены 13 экземплярами, как литыми, так и вырезанными из листа металла. 9 исследованных муфт изготовлены из «чистой» меди и сложных сплавов, как правило, с высоким содержанием цинка [Недашковский, 2002, с. 337338, 343-345, № 90, 117-122, 143; 2010б, с. 148149,151 , № 177]. Аналогичные изделия известны с поселений Нижнего Поволжья золотоордынского времени [Недашковский, 2001, c. 353,361 , рис. 2,1-26; Nedashkovsky, 2004, p. 47, 225, fig. 59,1-26], Среднего Поволжья, Хорезма, из курганов золотоордынских кочевников и Белоозера [Захаров, 2004, с. 194, табл. 192 , рис. $119,1-7]$.

Ножи были широко распространенными орудиями (их найдено 27) с длиной лезвия 4,711,3 см. По функциональному назначению можно выделить ножи универсальные и специальные (столярные).

Железные замки (рис. 5,2-5,7-9) представлены типом В (по Б.А. Колчину). Они состояли из скрепленных между собой двух цилиндров и запирающей дужки. Найдено 7 экземпляров изделий, два из них имеют удовлетворительную сохранность (рис. 5,2,4), прочие представлены фрагментами корпусов (рис. 5,3,5,7-9). Подвергнутый металлографическому анализу корпус замка изготовлен при помощи пайки медью [Недашковский, Семыкин, 2014, с. 36]. Два замка (рис. 5,3-4) происходят из ям 2 и 4 [Недашковский, 2011, с. $43-$ 44]. Данный тип замков был широко распространен в Древней Руси с середины XII по нача- ло XV в., а также на поселениях Среднего и Нижнего Поволжья, в Азаке и Старом Орхее [Древняя Русь..., 1997, с. 15, 252, табл. 6,3-5; Казаков, 1991, с. 74; Колчин, 1982, с. 160-161, рис. 3; Недашковский, 2000, с. 87-89, рис. 21,110; Руденко, 2011, с. 132, рис. 13,1-2,7; Савченкова, 1996, с. $40-43$, рис. $14,1-8,10,15,17]$.

Бронзовый замочек (рис. 5,1) был выполнен в форме коровки. Подобные изделия XI-XIII вв. известны с Болгарского городища [Полякова, 1996, с. 249-250, рис. 78,5] и из Херсонеса [Недашковский, 2000, с. 89].

Ключи представлены несколькими типами.

Тип 1 (1 экз.). Ключик (рис. 5,10) из «чистой» меди [Недашковский, 2002, с. 337-339, № 1]. Аналогичен новгородским железным ключам для замков типа Д (по Б.А. Колчину), который датируется XIV - серединой XV в.; схожее изделие найдено на Увекском городище [Древняя Русь..., 1997, с. 15, 252, табл. 6,25; Колчин, 1982, с. 160-161, рис. 3; Недашковский, 2000, с. 91, 93, рис. 23,5].

Тип 2 (1 экз.). Ключ к замку типа $\mathrm{B}, \mathrm{c}$ Н-образной рабочей частью (рис. 5,13 ), изготовлен из сырцовой стали [Недашковский, Семыкин, 2014, с. 37], найден в яме 4 [Недашковский, 2011, с. 44]. Подобные ключи бытовали на поселениях Среднего Поволжья [Казаков, 1991, с. 72, 74, рис. 29,13-14; Руденко, 2011, с. 133, рис. 14,8,10,12], они были распространены в Древней Руси, Нижнем Поволжье, Старом Орхее [Древняя Русь..., 1997 , с. 15,252 , табл. 6,1,6; Колчин, 1982 , с. 160-161, рис. 3 ; Недашковский, 2000, с. 91, 93 , рис. 23,6$]$.

Тип 3 (2 экз.). Ключи с отогнутой рабочей частью в виде скобы. Лучше сохранившееся изделие (рис. 5,11 ) изготовлено с применением технологии цементации, второй предмет из цельной стали [Недашковский, Семыкин, 2014, с. 37] был найден в яме 4 (№ 53, -79 см) раскопа I [Недашковский, 2011, c. 44]. Подобные ключи найдены в Биляре [Руденко, 2006, с. 132, рис. 21,20-22].

Тип 4 (1 экз.). Ключ с рабочей частью в виде буквы Н (рис. 5,12) с двумя выступами с одной из сторон (сохранился один из них) от замка типа Г (по Б.А. Колчину); изготовлен из сырцовой стали [Недашковский, Семыкин, 2014, с. 37]. Аналогии найдены на памятниках Древней Руси середины XIII - середины 
XV в. [Древняя Русь..., 1997, с. 15, 252, табл. 6,15; Колчин, 1982, с. 160-161, рис. 3] и Среднего Поволжья [Казаков, 1991, с. 72, 74, рис. 29,13; Руденко, 2006, с. 133-134, рис. $22,13-14,22-23,23,7]$.

Тип 5 (2 экз.). Ключи с раздвоенной рабочей частью. Хорошо сохранившийся экземпляр имеет окончания в виде двух скоб (рис. 5,6) и откован из сырцовой стали [Недашковский, Семыкин, 2014, с. 37]. Еще один фрагмент ключа этого типа с несохранившимися окончаниями рабочей части, откованный из цельностальной заготовки [Недашковский, Семыкин, 2014, c. 37], найден в 2000 г. в яме 4 раскопа I (№ 77, -111 см). Подобные предметы известны в Древней Руси (ключи к замкам типа Г) и Среднем Поволжье [Древняя Русь..., 1997, с. 15, 252, табл. 6,20; Колчин, 1982, с. 160-161, рис. 3; Руденко, 2006, с. 134, рис. 23,2].

Представляет интерес факт, что все замки и ключи, найденные в сооружениях, происходят из жилища (яма 4 раскопа I - замок и 3 ключа), жилища, совмещенного с погребом (яма 2 раскопа I - замок и ключ), и крупного подпрямоугольного сооружения (яма 1 раскопа II - замок), вероятно, также жилого по назначению.

Золотоордынская неполивная гончарная керамика Хмелевского I селища представлена значительным количеством форм, многие из которых хорошо сохранились (рис. 6-7). Посуда присутствует лощеная (5,7-22,3 \% на разных раскопах; рис. 4,4, 6,2, 7) и нелощеная (77,7-94,3 \%; рис. $4,2,6,1$ ); керамика хорошего (рис. 4,4) обжига $(53,3-63,5 \%)$ количественно несколько преобладает над плохо обожженной (рис. 4,2, 6-7) керамикой $(36,5-46,7 \%)$. Коричневой посуды (рис. 4,2,4,6-7) на разных раскопах 44,3-85,3 \%, красной $-7,1-33,7 \%$, серой $1-7,6 \%$, бурой $-0,5-$ $19,6 \%$, желтой - не более $0,7 \%$.

Имеются кувшины (рис. 6,5, 7), туваки (рис. 6,1), миски, крышки, фляги, нелощеные горшковидные сосуды хорошего обжига с одной ручкой.

Один из кувшинообразных сосудов имеет диаметр венчика - 10,5 см, диаметр тулова $-19,8$ см и высоту $-25,6$ см (рис. 7). Второе изделие сохранилось хуже, диаметр его венчика - 12,6 см, оно имеет ручку (рис. 6,5). Кувшины орнаментированы вертикальным лощением и прочерченными горизонтальными ли- ниями по горловине и тулову. Подобные сосуды известны из золотоордынских напластований Болгарского городища [Кокорина, 2002, с. 325 , рис. 71,8 ; Хлебникова, 1988 , с. $58-59$, рис. $36,4,37,7]$.

Тувак (сунак) имеет диаметр венчика 15,7 см, диаметр тулова - 11,1 см и высоту 12,4 см (рис. 6,1). Сходные по форме гончарные сосуды известны из материалов Среднего Поволжья золотоордынского времени, а также из золотоордынских городов Нижнего Поволжья, Поднестровья, Приазовья и из Средней Азии [Волков, 1992, с. 5-6, 20, табл. 1, А16, Б6; Кокорина, 2002 , с. $73,147,293,341$, рис. $39,18,86,10$ 12, 14; Недашковский, 2000, с. 98-99, 101-102, рис. 27,1-3; Федоров-Давыдов, 2001, с. 164167, табл. 90, 91,1; Хлебникова, 1988, с. 88, 9092, pис. 66,1-5, 7, 68; Fyodorov-Davydov, 1984, fig. 47,3].

Золотоордынская керамика имеет примесь мелкого песка в тесте, иногда посуда дополнена красным ангобом. Керамика украшена орнаментом в виде прочерченных горизонтальных линий (рис. 4,2,4, 6,5, 7), многорядной и однорядной волны, оттисков гребенчатого штампа, фестонов и оттисков палочки; есть сосуды, покрытые лощением (рис. 4,4, $6,5,7)$, в том числе горизонтальным и вертикальным (рис. $6,5,7)$, а также в виде зигзагообразных вертикальных линий.

Керамические напрясла (6 экз.) были изготовлены из стенок золотоордынской неполивной керамической посуды с примесью песка в тесте, их форма округлая (рис. 4,2,4). Сосуды, использованные для изготовления напрясел, были в двух случаях лощеными (рис. 4,4), в остальных - нелощеными (рис. 4,2 ); четыре сосуда были обожжены хорошо (рис. 4,4$)$ и два (рис. 4,2 ) имели плохой обжиг. Напрясла имеют в двух случаях красный и в четырех - коричневый (рис. 4,2,4) цвет. Размеры пяти небольших изделий (рис. 4,2,4): диаметры - 27-48 мм, толщина - 58 мм, диаметр отверстий - 4-7 мм. Крупный массивный предмет с неровными краями имеет диаметр 65 мм, толщину - 8 мм и диаметр отверстия - 6 мм.

Фрагменты древнерусской керамики имеют примесь в тесте дресвы и песка (рис. 6,4), а также только песка; цвет посуды коричневый (рис. 6,4) или серый. На некото- 
рых изделиях нанесен орнамент в виде горизонтальных линий. Древнерусская керамика из слоя раскопа I представлена 6 фрагментами (5 из нижних горизонтов), в ямах раскопа I найдено 34 фрагмента. Древнерусская керамика на раскопе II не выявлена, в слое раскопа III ее найдено 35 фрагментов [Недашковский, 2011, с. 42-46]. Данная горшковидная посуда, датирующаяся второй половиной XIII $\mathrm{XIV}$ в., является преимущественно кухонной, так как зачастую наружная сторона ее покрыта сажей и нагаром. Находки древнерусской керамики на раскопах и в шурфе на поселении составляют от 0 до 3,7 \% от всей керамической посуды. Обращает на себя внимание низкий процент такой посуды в материале малого золотоордынского города по сравнению с некоторыми синхронными поселениями сельского типа.

Примечательно, что ближе к центру селища (раскопы I, III) древнерусская керамика присутствует в значительном количестве, тогда как ближе к окраине (раскоп II) она полностью отсутствует, такая же закономерность характерна и в отношении мордовской посуды.

Фрагменты мордовской посуды имеют в тесте примесь шамота (рис. 6,2-3). Мордовская лепная керамика из слоя раскопа I представлена 6 фрагментами, из ям - 12 фрагментами. На раскопе II лепная посуда не выявлена, в слое раскопа III найдено 4 фрагмента мордовской керамики (рис. 6,2). Находки такой грубой лепной посуды на селище не столь многочисленны, как находки древнерусских сосудов, и составляют на раскопах не более $0,4 \%$ от всей керамики [Недашковский, 2011, с. 42-46].

Из общей массы неполивной керамической посуды выделяются трапезундские ам$\phi o p b l$, их найдено при раскопках на селище 9 фрагментов. Из них 5 обнаружено в ямах раскопа I, а 4 - на раскопе III. Один из фрагментов амфоры происходит из подъемного материала. Трапезундские амфоры имеют красно-оранжевый цвет, с мелким рифлением и белым ангобом, а также примесь в тесте мелкого песка и слюды.

Многочисленные находки фрагментов кашинной и красноглиняной поливной поcyды встречены в подъемном материале, из которого происходят также фрагменты при- донной части селадонового сосуда с гравировкой и буро-коричневой «железной пятой» на свободной от поливы наружной стороне донца, и чаши с люстровой росписью. Кашинная керамика встречается в значительном количестве в слое (42 фр.) и сооружениях (53 фр.) раскопа I, тогда как на остальных раскопах она зафиксирована в незначительных количествах: 3 фрагмента на раскопе II и 5 фрагментов на раскопе III [Недашковский, 2011, с. 4246]. Красноглиняная поливная посуда также преобладает в слое и сооружениях раскопа I - ее выявлено 47 фрагментов, на раскопе II найдено 13 фрагментов, а на раскопе III такая посуда не обнаружена. Штампованной керамики найдено 14 фрагментов, из них 9 в слое и 5 в ямах раскопа I [Недашковский, 2011, c. 42, 44-45].

При раскопках найдено довольно значительное количество глиняной обмазки, фрагментов обмазки тандыра, камней и костей животных. Все эти находки (в особенности кости) в массе встречаются в слое и ямах раскопа I, тогда как на раскопах II-III их концентрация резко падает. Этот факт подтверждает локализацию центра поселения в районе раскопа I, которая засвидетельствована и другими находками, в частности неполивной керамической посудой.

Представленная коллекция индивидуальных находок золотоордынского времени, происходящая с Хмелевского I селища, также позволяет сделать некоторые выводы. Сравним приведенные материалы с изделиями тех же категорий, происходящими с Увекского городища [Недашковский, 2000, с. 67-93; 2001], на месте которого располагался близлежащий крупный город Укек. В материалах с Хмелевского I селища, в отличие от Укека, отсутствуют копья, булавы, кистени, кинжалы, боевые ножи, стремена и серебряные сосуды. Обращает на себя внимание многократное преобладание в материалах Увекского городища топоров, керамических бомб, заклепок от металлических сосудов, бронзовых замочков и муфт ножей. Напротив, отмечается наличие в материалах Хмелевского I селища железных подпружной пряжки и кольца от узды, отсутствующих на Увекском городище.

По своим археологическим характеристикам Хмелевское I селище являлось па- 
L.F. Nedashkovsky, M.B. Shigapov. Metalware and Pottery from the Hmelevka I Settlement

мятником городского типа, как и более крупное по размерам Увекское городище, однако приведенные выше различия в материальной культуре, по нашему мнению, отражают некоторые отличия быта и культуры населения малого и крупного золотоордынского города соответственно. Жители круп- ного города (особенно оседлая золотоордынская аристократия, как раз и проживавшая преимущественно в городах), очевидно, в большей степени были связаны с военным делом и торговлей, а население малого города - с подсобными земледелием и скотоводством. 


\section{ИЛЛЮСТРАЦИИ}

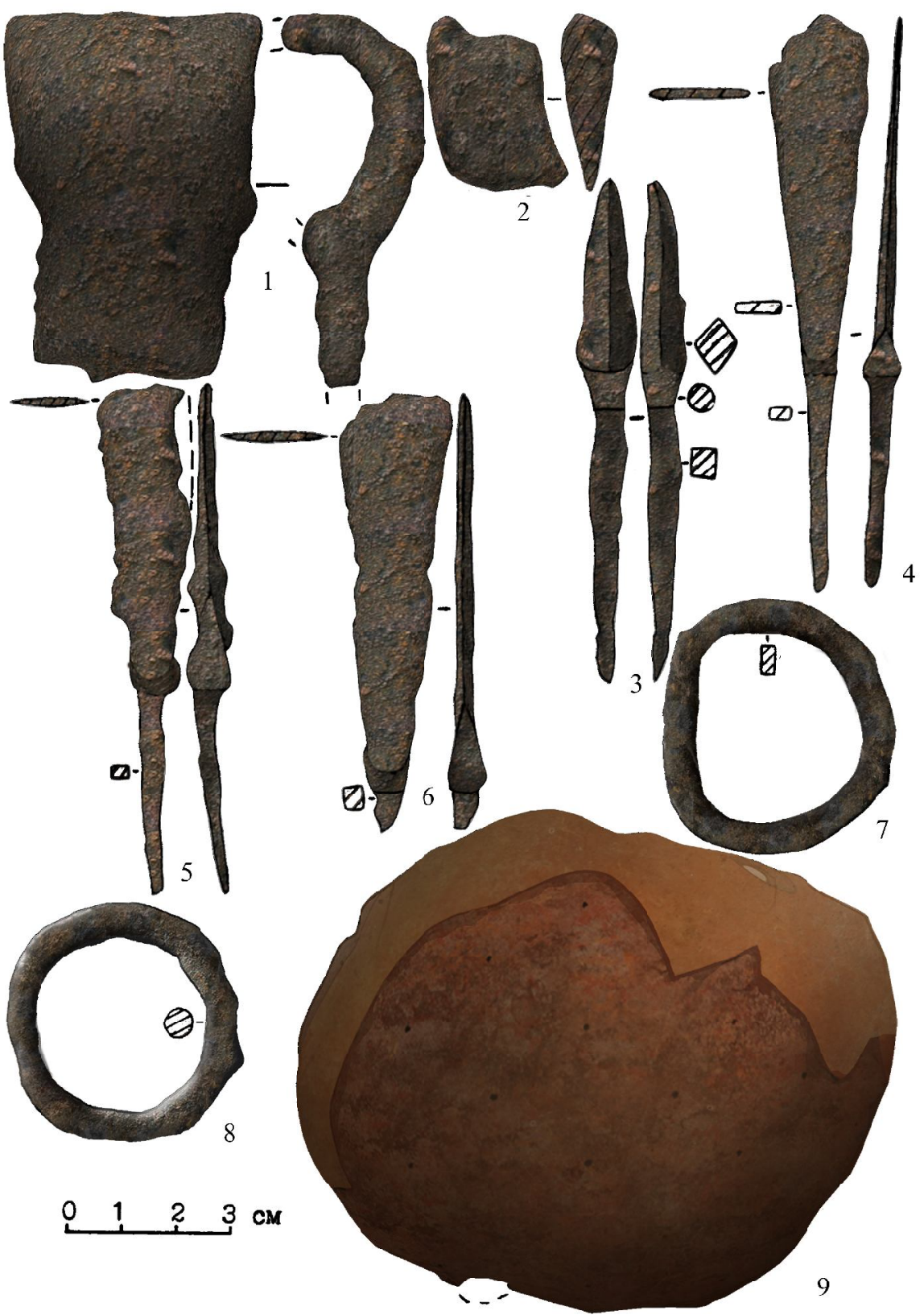

Рис. 1. Железные фрагменты топоров (1-2), наконечники стрел (3-6), рамка пряжки (7), кольцо (8) и фрагмент керамической бомбы (9) с Хмелевского I селища:

1, 3, 5 - Саратовский областной музей краеведения, раскоп I-1999: 1, 5 - яма 2 (№ 14, -148 см; № 12, -154 см); 3 - культурный слой (№ 3, -61см). 2, 7-9 - Саратовский областной музей краеведения, подъемный материал Л.Ф. Недашковского 2001 (2), 1998 (7, 9) и 2000 (8) гг. 4 - Научно-исследовательская археологическая лаборатория Саратовского государственного университета. 6 - Саратовский областной музей краеведения, раскоп I-2000, яма 5 (№ 79, -185 cм)

Fig. 1. Iron fragments of axes (1-2), arrowheads (3-6), framework of buckle (7), ring (8) and fragment of ceramic bomb (9) from the Hmelevka I settlement:

1, 3, 5 - Saratov regional museum of regional ethnography, trench I-1999: 1, 5 - pit 2 (no. 14, -148 cm; no. 12, -154 cm);

3 - cultural layer (no. 3, -61 cm). 2, 7-9-Saratov regional museum of regional ethnography, investigations by L.F. Nedashkovsky, 2001 (2), 1998 (7, 9) and 2000 (8). 4 - Research Archaeological laboratory

of the Saratov State University. 6 - Saratov regional museum of regional ethnography, trench I-2000, pit 5 (no. $79,-185 \mathrm{~cm}$ ) 


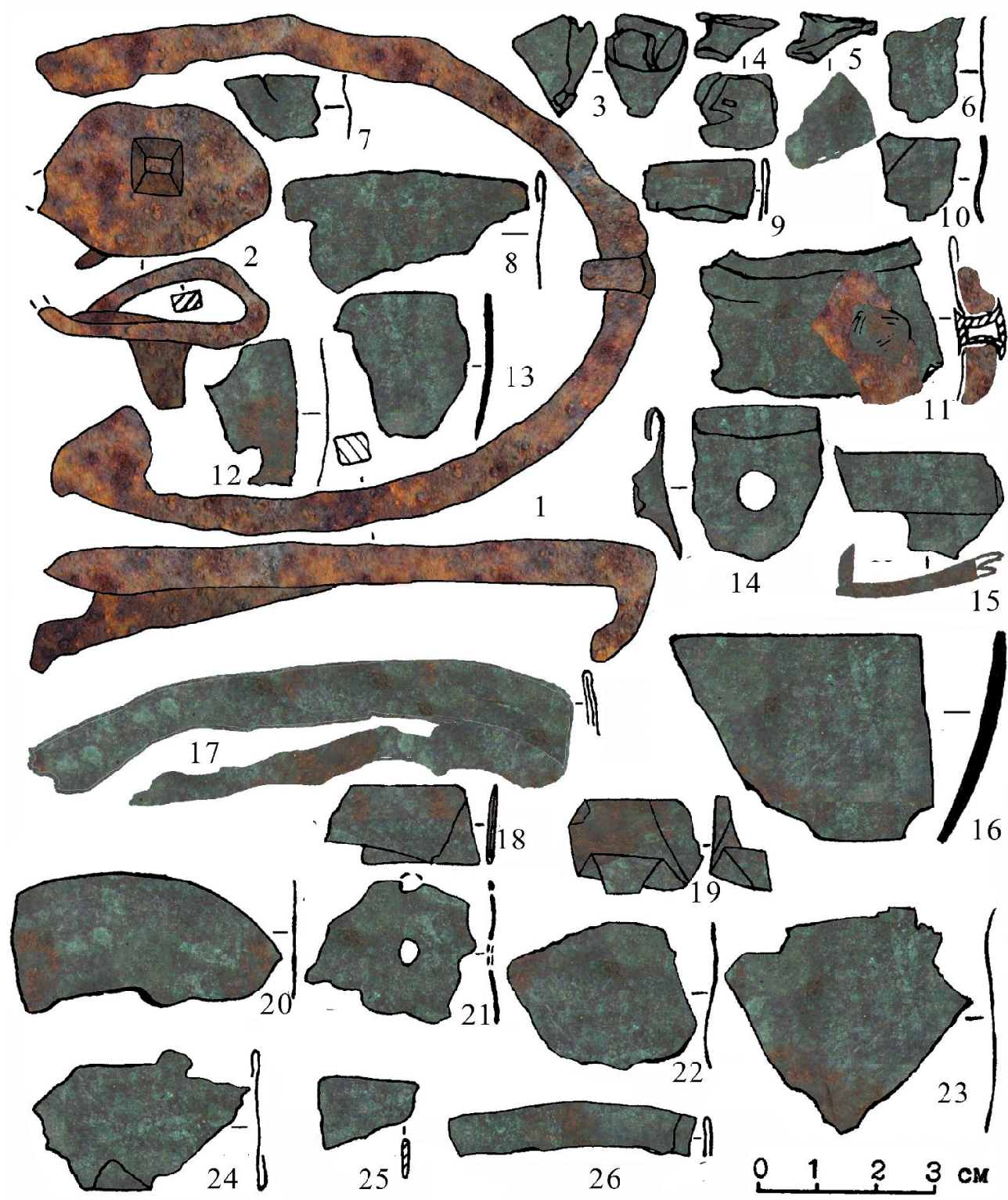

Рис. 2. Подкова (1), ледоходный шип (2), заклепки (3-5), фрагменты кованых (8-9, 11, 14, 17, 22-23, 26) и литых $(13,16)$ сосудов и обломки листов $(6-7,10,12,15,18-21,24-25)$ с Хмелевского I селища:

1-2 - железо; 3-10, 12-25 - бронза; 11 - железо и бронза. 1, 6-7, 12, 14, 17, 24 - Саратовский областной музей краеведения, раскоп I-2000: 1 - яма 5 (№ 52, -110 см); 6-7, 24 - яма 4 (№ 20, -48 см); 12, 14, 17 - культурный слой

(№ 15, -51 см; № 3, -43 см; № 67, -91 см). 2-5, 8-9, 11, 13, 15-16, 18-23, 26- Саратовский областной музей краеведения, подъемный материал Л.Ф. Недашковского 1998 (2, 15, 18-19, 21), 2000 (3-5, 8, 11, 13, 16, 20, 22-23), 2002 (9) и 2001 (26) гг. 10, 25 - Саратовский областной музей краеведения, раскоп I-1999, яма 2 (№ 26, -214см; № 46, $-266 \mathrm{~cm}$ )

Fig. 2. Horseshoe (1), debacle thorn (2), rivets (3-5), fragments of forged $(8-9,11,14,17,22-23,26)$ and cast $(13,16)$ vessels and fragments of sheets $(6-7,10,12,15,18-21,24-25)$ from the Hmelevka I settlement:

1-2 - iron; 3-10, 12-25-bronze; 11 - iron and bronze. 1, 6-7, 12, 14, 17, 24 - Saratov regional museum of regional ethnography, trench I-2000: 1 - pit 5 (no. $52,-110 \mathrm{~cm}$ ); 6-7, 24 - pit 4 (no. $20,-48 \mathrm{~cm}$ );

$12,14,17$ - cultural layer (no. $15,-51 \mathrm{~cm}$; no. $3,-43 \mathrm{~cm}$; no. 67, -91 cm). 2-5, 8-9, 11, 13, 15-16, 18-23, $26-$ Saratov regional museum of regional ethnography, investigations by L.F. Nedashkovsky, $1998(2,15,18-19,21), 2000(3-$

$5,8,11,13,16,20,22-23), 2002$ (9) and 2001 (26). 10, 25 - Saratov regional museum of regional ethnography, trench I-1999, pit 2 (no. $26,-214 \mathrm{~cm}$; no. $46,-266 \mathrm{~cm}$ ) 

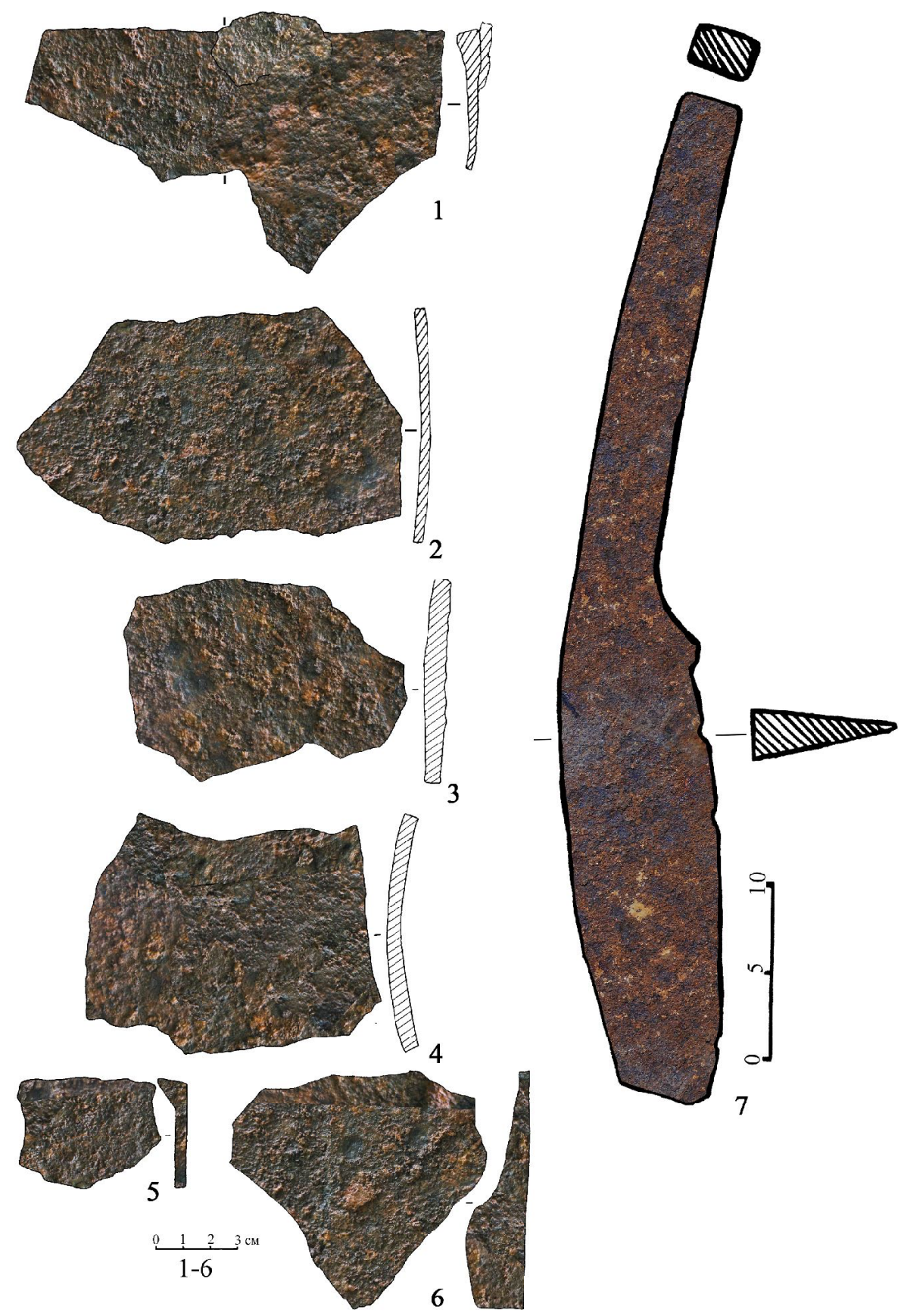

Рис. 3. Фрагменты чугунных котлов (1-6) и железное чересло (7) с Хмелевского I селища:

1-2 - Саратовский областной музей краеведения, раскоп I-2000, яма 5 (№ 49, -87 см).

3-7 - Саратовский областной музей краеведения, подъемный материал Л.Ф. Недашковского 2001 г.

Fig. 3. Fragments of cast-iron cauldrons (1-6) and iron plough blade (7) from the Hmelevka I settlement:

1-2 - Saratov regional museum of regional ethnography, trench I-2000, pit 5 (no. 49, $-87 \mathrm{~cm}$ ).

3-7 - Saratov regional museum of regional ethnography, investigations by L.F. Nedashkovsky, 2001 


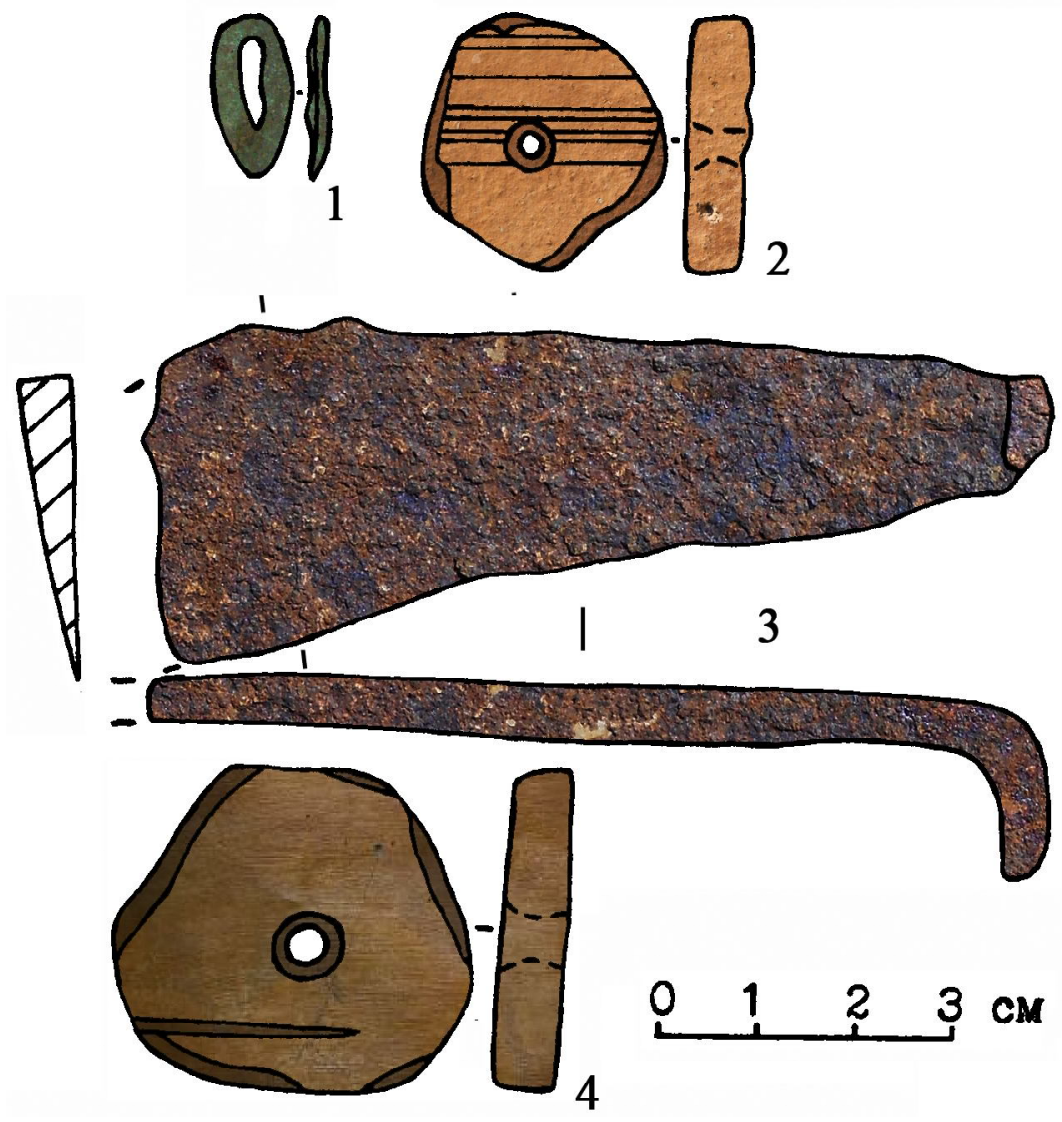

Рис. 4. Бронзовая муфта ножа (1), керамические напрясла из стенок сосудов $(2,4)$ и фрагмент железной косы (3) с Хмелевского I селища:

1 - Саратовский областной музей краеведения, подъемный материал Л.Ф. Недашковского 2000 г., № НВСП 45220/25. 2-4 - Саратовский областной музей краеведения, раскоп I-2000, яма 4: 2 - № 57, -71 см, № НBCП 45268/31; 3 - № 40, -101 см, № НВСП 45220/45; 4 - № 42, -108 cм, № НВСП 45268/41

Fig. 4. Bronze coupling of knife (1), ceramic spindle-whorls made from the walls of vessels $(2,4)$ and fragment of the iron scythe (3) from the Hmelevka I settlement:

1 - Saratov regional museum of regional ethnography, investigations by L.F. Nedashkovsky, 2000, no. NVSP 45220/25.

2-4 - Saratov regional museum of regional ethnography, trench I-2000, pit 4: 2 - no. 57, $-71 \mathrm{~cm}$, no. NVSP 45268/31; 3 - no. 40, -101 cm, no. NVSP 45220/45; 4 - no. 42, -108 cm, no. NVSP 45268/41 


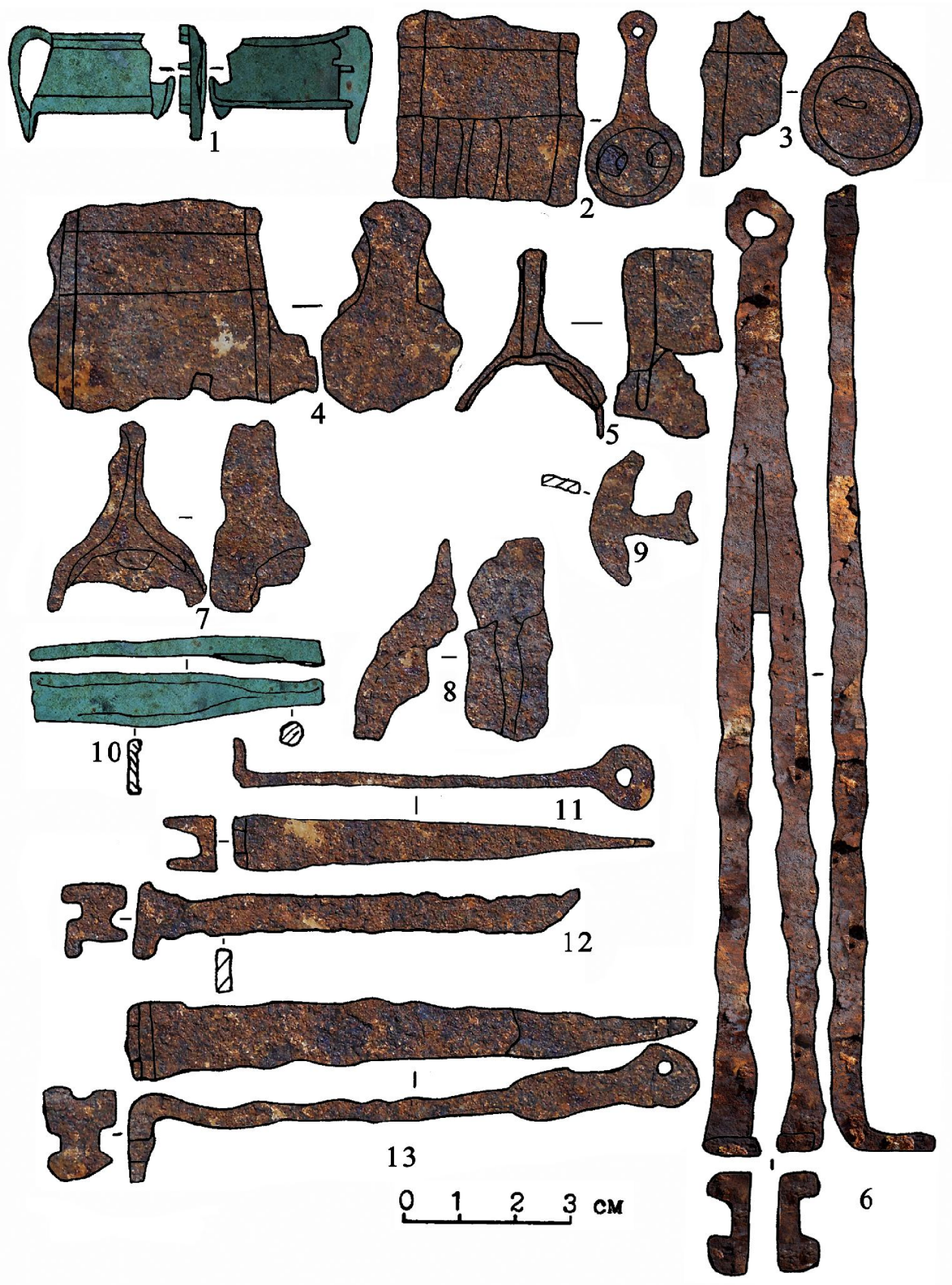

Рис. 5. Бронзовые половинка замочка $(1)$, ключик (10), железные замки $(2-5,7-9)$ и ключи $(6,11-13)$ с Хмелевского I селища:

1, 7-11 - Саратовский областной музей краеведения, подъемный материал Л.Ф. Недашковского 1998 (1), 2001 (7, 9) и $2000(8,10-11)$ гг,; 2, 12 - Саратовский областной музей краеведения, раскоп I-2000, культурный слой (№ 46, -87 см; № 38, -57 см); 3-4, 6, 13 - Саратовский областной музей краеведения, раскоп I-1999: 3, 13 - яма 4 (№ 47, -143 см; № 55, -98 см); 4, 6 - яма 2 (№ 13, -187 см; № 31, -232 см); 5 - Саратовский областной музей краеведения, раскоп II-2000, яма 1 (№ 14, $-85 \mathrm{~cm}$ )

Fig. 5. Bronze half of lock (1), key (10), iron locks (2-5, 7-9) and keys (6, 11-13) from the Hmelevka I settlement:

1, 7-11 - Saratov regional museum of regional ethnography, investigations by L.F. Nedashkovsky, $1998(1), 2001(7,9)$ and $2000(8,10-11) ; 2,12$ - Saratov regional museum of regional ethnography, trench I-2000, cultural layer

(no. 46, $-87 \mathrm{~cm}$; no. 38, $-57 \mathrm{~cm}$ ); 3-4, 6, 13 - Saratov regional museum of regional ethnography, trench I-1999: 3,13 - pit 4 (no. $47,-143 \mathrm{~cm}$; no. $55,-98 \mathrm{~cm}$ ); 4, 6 - pit 2 (no. 13, $-187 \mathrm{~cm} ;$ no. $31,-232 \mathrm{~cm}$ );

5 - Saratov regional museum of regional ethnography, trench II-2000, pit 1 (no. $14,-85 \mathrm{~cm}$ ) 


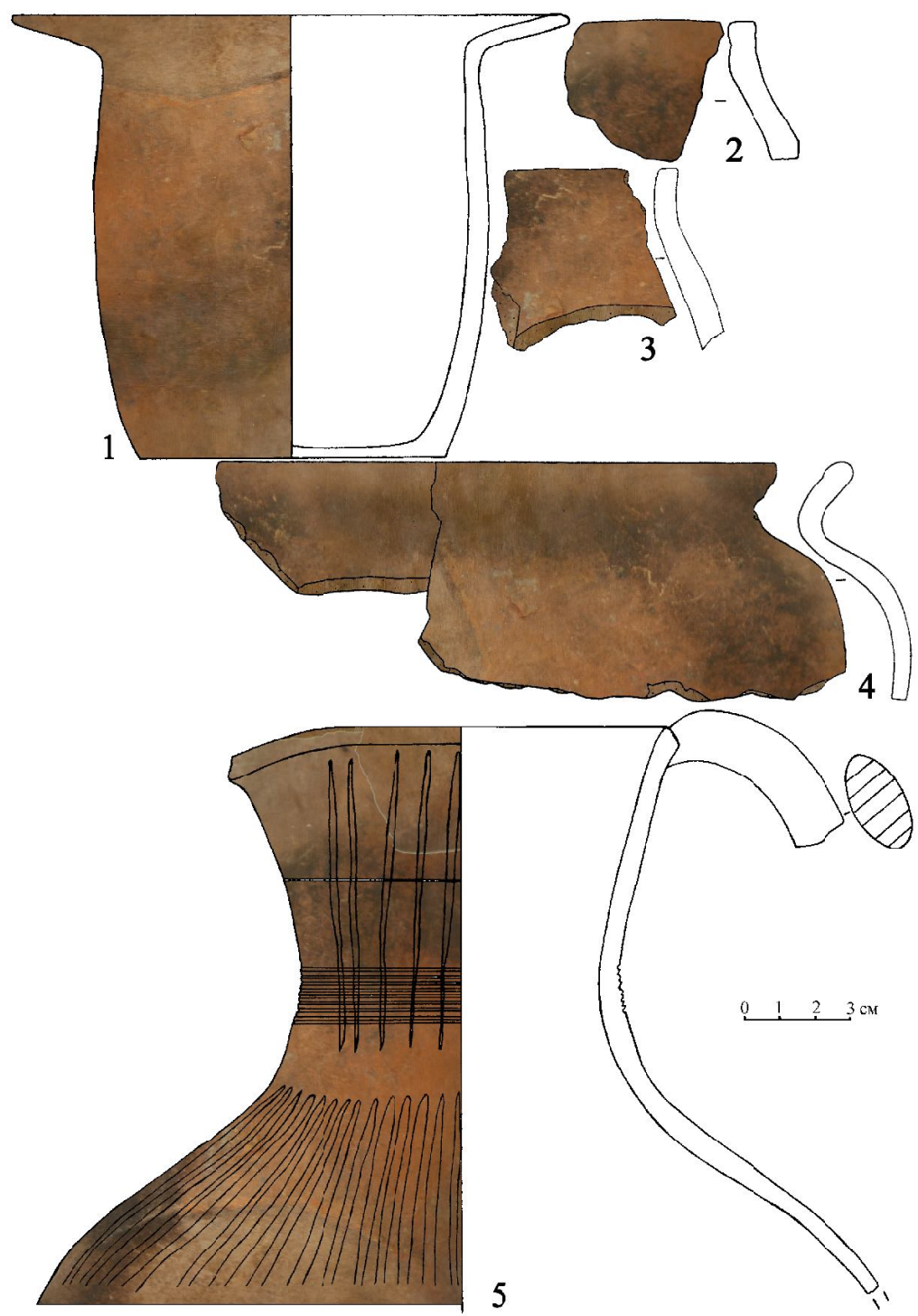

Рис. 6. Золотоордынские красноглиняные неполивные тувак (1), кувшин (5), фрагменты мордовской (2-3) и древнерусской (4) керамики с Хмелевского I селища:

1, 5 - Саратовский областной музей краеведения, раскоп I-1999, яма 4. 1 - № НВСП 45093/4; 5 - № НВСП 45093/5; 2 - Саратовский областной музей краеведения, раскоп III-2001, культурный слой;

3 - Саратовский областной музей краеведения, подъемный материал Л.Ф. Недашковского 1995 г.;

4 - Саратовский областной музей краеведения, шурф Л.Ф. Недашковского 1995 г.

Fig. 6. Golden Horde red-clay unglazed tuvak (1), jar (5), fragments of Mordvin (2-3) and Old Russian (4) pottery from the Hmelevka I settlement:

1, 5 - Saratov regional museum of regional ethnography, trench I-1999, pit 4. 1 - no. NVSP 45093/4;

5 - no. NVSP 45093/5; 2 - Saratov regional museum of regional ethnography, trench III-2001, cultural layer;

3 - Saratov regional museum of regional ethnography, investigations by L.F. Nedashkovsky, 1995;

4 - Saratov regional museum of regional ethnography, probe trench by L.F. Nedashkovsky, 1995 
Л.Ф. Недашковский, М.Б. Шигапов. Металлические изделия и керамика с Хмелевского І селища

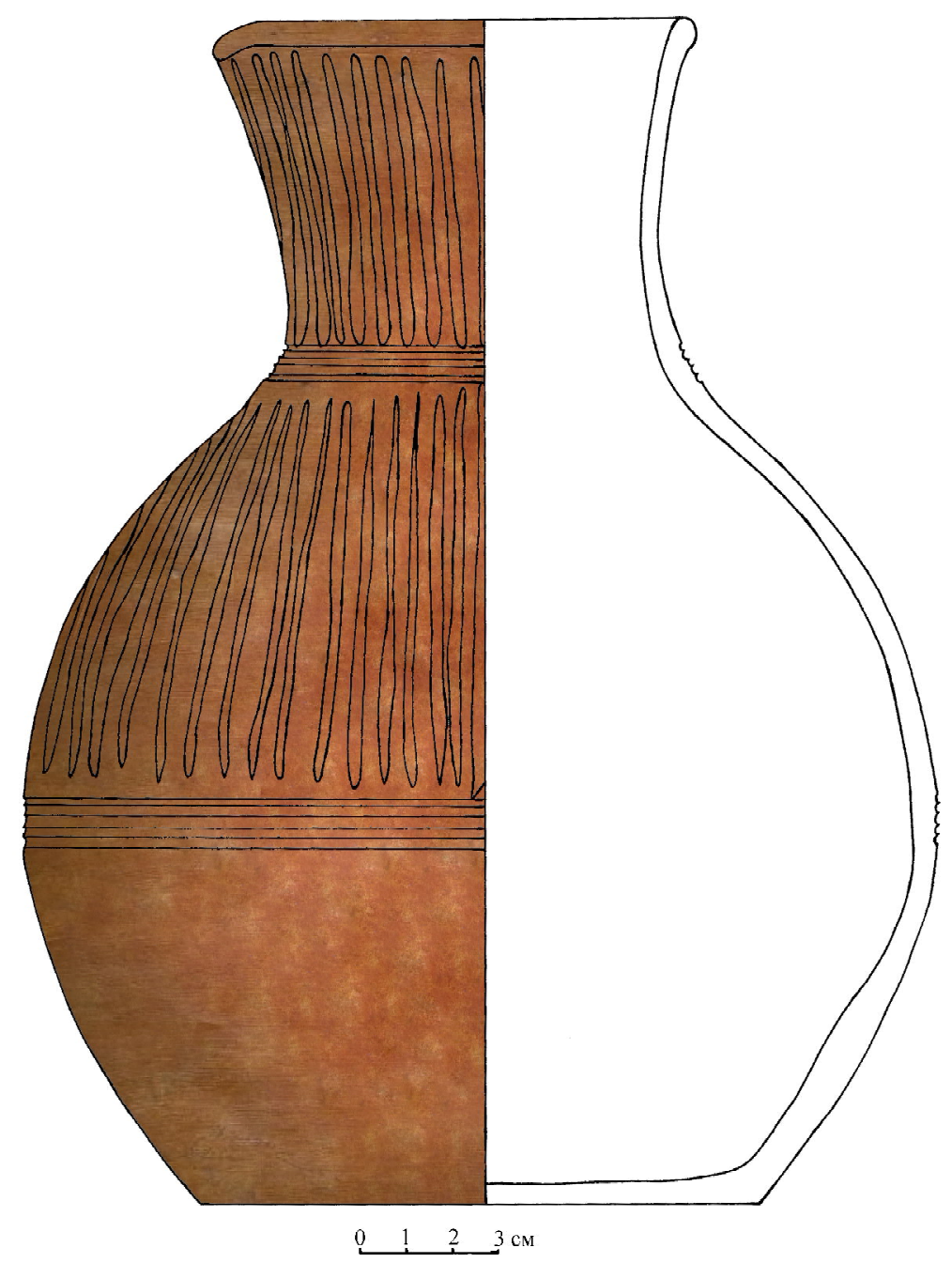

Рис. 7. Золотоордынский красноглиняный неполивной кувшинообразный сосуд из ямы 4 раскопа I-1999 с Хмелевского I селища. Саратовский областной музей краеведения, № НВСП 45093/3,6

Fig. 7. Golden Horde red-clay unglazed jar-like vessel from pit 4 of trench I-1999 from the Hmelevka I settlement. Saratov regional museum of regional ethnography, no. NVSP 45093/3,6 


\section{СПИСОК ЛИТЕРАТУРЫ}

Волков И. В., 1992. Керамика Азова XIV-XVIII вв. (Классификация и датировка) : автореф. дис. ... канд. ист. наук. М. 24 с.

Древняя Русь. Быт и культура, 1997. М. : Наука. 368 с. Захаров С. Д., 2004. Древнерусский город Белоозеро. М. : Индрик. 592 с.

Казаков Е. П. 1991. Булгарское село Х-ХІІІ веков низовий Камы. Казань : Татар. кн. изд-во. 176 с.

Кирпичников А. Н., 1966. Древнерусское оружие. Вып. 2. Копья, сулицы, боевые топоры, булавы, кистени IX-XIII вв. М. ; Л. : Наука. 147 с.

Кирпичников А. Н., 1973. Снаряжение всадника и верхового коня на Руси IX-XIII вв. Л. : Наука. 140 с.

Кокорина Н. А., 2002. Керамика Волжской Булгарии второй половины XI - начала XV в. : (К проблеме преемственности булгарской и булгаро-татарской культур). Казань : Ин-т истории. $383 \mathrm{c}$.

Колчин Б. А., 1982. Хронология новгородских древностей // Новгородский сборник. 50 лет раскопок Новгорода. М. : Наука. С. 156-177.

Медведев А. Ф., 1959. Оружие Новгорода Великого // Материалы и исследования по археологии СССР. Т. 65. М. : Изд-во АН СССР. С. 121-191.

Медведев А. Ф., 1966а. Ручное метательное оружие (лук, стрелы, самострел) VIII-XIV вв. М. : Наука. 182 c.

Медведев А. Ф., 1966б. Татаро-монгольские наконечники стрел в Восточной Европе // Советская археология. № 2. С. 50-60.

Недашковский Л. Ф., 2000. Золотоордынский город Укек и его округа. М. : Вост. лит. 224 с.

Недашковский Л. Ф., 2001. Металлические изделия и литейные формы с Увекского городища // Древние ремесленники Приуралья : материалы Всерос. науч. конф. (г. Ижевск, 21-23 нояб. 2000 г.). Ижевск : УИИЯЛ УрО РАН. С. 349-364.

Недашковский Л. Ф., 2002. Химический состав изделий из цветных металлов с золотоордынских поселений центральной части Саратовской области // Нижневолжский археологический вестник. Вып. 5. С. 335-347.

Недашковский Л. Ф., 2010а. Золотоордынские города Нижнего Поволжья и их округа. М. : Вост. лит. $351 \mathrm{c}$.

Недашковский Л. Ф., 2010б. Химический состав изделий из цветных металлов с золотоордынских селищ округи Укека // Интеграция археологических и этнографических исследований. Ч. 1. Казань : ИИ АН РТ. С. 147-151.

Недашковский Л. Ф., 2011. Исследования Хмелевского I селища // Ученые записки Казанского университета. Серия «Гуманитарные науки». Т. 153, кн. 3. Казань. С. 39-50.
Недашковский Л. Ф., Семыкин Ю. А., 2014. Результаты металлографического анализа изделий из черного металла с золотоордынских памятников Нижнего Поволжья (по материалам Хмелевского I и Багаевского селищ) // Ученые записки Казанского университета. Серия «Гуманитарные науки». Т. 156, кн. 3. С. 31-43.

Полякова Г. Ф., 1996. Изделия из цветных и драгоценных металлов // Город Болгар: Ремесло металлургов, кузнецов, литейщиков. Казань : Татполиграф. С. 154-268.

Руденко К. А., 2006. Булгарский улус Золотой Орды (особенности материальной культуры) // Татарская археология. № 3-4 (18-19). С. 28-137.

Руденко К. А., 2011. Города и села Булгарского улуса Золотой Орды (особенности материальной культуры) // Татарская археология. № 1-2 (2021). C. $32-151$.

Савченкова Л. Л., 1996. Черный металл Болгара. Типология // Город Болгар: Ремесло металлургов, кузнецов, литейщиков. Казань : Татполиграф. С. 5-88.

Федоров-Давыдов Г. А., 1966. Кочевники Восточной Европы под властью золотоордынских ханов. Археологические памятники. М. : Изд-во Моск. ун-та. 274 с.

Федоров-Давыдов Г. А., 2001. Золотоордынские города Поволжья: Керамика. Торговля. Быт. М. : Изд-во МГУ. 256 с.

Хлебникова Т. А., 1988. Неполивная керамика Болгара // Город Болгар: Очерки ремесленной деятельности. М. : Наука. С. 7-102.

Fyodorov-Davydov G. A., 1984. The Culture of the Golden Horde Cities. Translated from the Russian by H. Bartlett Wells / BAR. International Series. 198. Oxford. $278 \mathrm{p}$.

Nedashkovsky L. F., 2004. Ukek: The Golden Horde city and its periphery / BAR. International Series. 1222. Oxford: Archaeopress. 253 p.

\section{REFERENCES}

Volkov I.V., 1992. Ceramics of Azov of the XIVXVIII centuries. (Classification and dating). Cand. hist. sci. abs. diss. Moscow. 24 p. (in Russian).

Ancient Russia. Life and culture, 1997. Moscow, Nauka Publ. 368 p. (in Russian).

Zakharov S.D., 2004. Old Russian city Beloozero. Moscow, Indrik Publ. 592 p. (in Russian).

Kazakov E.P., 1991. Bulgar village of the X$X I I I$ centuries in the Low Kama region. Kazan, Tatar. kn. izd-vo. 176 p. (in Russian).

Kirpichnikov A.N., 1966. Old Russian arms. Iss. 2. Spears, javelins, battle axes, maces, kisten's of 
$I^{\text {th }}$-XIII ${ }^{\text {th }}$ centuries. Moscow, Leningrad, Nauka Publ. 147 p. (in Russian).

Kirpichnikov A.N., 1973. Equipment of a horseman and horse on Rus' of the IX-XIII centuries. Leningrad, Nauka Publ. 140 p. (in Russian).

Kokorina N.A., 2002. Pottery of the Volga Bulgaria of the second half of $11^{\text {th }}$ - beginning of $15^{\text {th }}$ century. (To the problem of the continuity of Bulgarian and Bulgar-Tatar cultures). Kazan, Institute of History. 383 p. (in Russian).

Kolchin B.A., 1982. Chronology of the Novgorod antiquities. Novgorodsky sbornik. 50 let raskopok Novgoroda. Moscow, Nauka Publ., pp. 156-177. (in Russian).

Medvedev A.F., 1959. Arms of Novgorod the Great. Materialy $i$ issledovaniya po arkheologii SSSR, no. 65. Moscow, Publishing house of the USSR Academy of Sciences, pp. 121-191. (in Russian).

Medvedev A.F., 1966a. Hand-throwing arms (bow, arrows, crossbow) of VIII-XIV centuries. Moscow, Nauka Publ. 182 p. (in Russian).

Medvedev A.F., 1966b. The Tatar-Mongolian arrowheads in East Europe. Sovetskaya Arkheologiya, no 2, pp. 50-60. (in Russian).

Nedashkovsky L.F., 2000. The Golden Horde city Ukek and its regions. Moscow, Vostochnaya literatura Publ. 224 p. (in Russian).

Nedashkovsky L.F., 2001. Metal wares and casting moulds from the Uvek site. Drevnie remeslenniki Priuralia: materialy Vseros. nauch. konf. (g. Izhevsk, 21-23 noiab. 2000 g.). Izhevsk, Udmurt Institute of history, language and literature, Ural branch of RAS, pp. 349-364. (in Russian).

Nedashkovsky L.F., 2002. The chemical composition of the non-ferrous articles from the Golden Horde settlements of the central part of Saratov region. The Lower Volga Archaeological Bulletin, iss. 5, pp. 335-347. (in Russian).

Nedashkovsky L.F., 2010a. The Golden Horde cities of the Low Volga region and their periphery. Moscow, Vostochnaya literatura Publ. 351 p. (in Russian).

Nedashkovsky L.F., 2010b. The chemical composition of the non-ferrous articles from the Golden Horde settlements of Ukek region. Integratsiya arkheologicheskih $i$ etnograficheskih issledovany. Part. 1. Kazan, Institute of history
Of Academy of Sciences of the Republic of Tatarstan, pp. 147-151. (in Russian).

Nedashkovsky L.F., 2011. Researches of the Hmelevskoe I settlement. Uchenye zapiski Kazanskogo universiteta. Seriia «Gumanitarnye nauki», vol. 153, book. 3, pp. 39-50. (in Russian).

Nedashkovsky L.F., Semykin Yu.A., 2014. The results of metallographic analysis of ferrous objects from the Golden Horde sites of the Low Volga region (on the materials of Hmelevka I and Bagaevka settlements). Uchenye zapiski Kazanskogo universiteta. Seriia "Gumanitarnye nauki», vol. 156, book. 3, pp. 31-43. (in Russian).

Polyakova G.F., 1996. Wares from non-ferrous and precious metals. Gorod Bolgar: Remeslo metallurgov, kuznetsov, liteyshchikov. Kazan, TatpoligrafPubl., pp. 154-268. (in Russian).

Rudenko K.A., 2006. Bulgarian ulus of the Golden Horde (characteristics of material culture). Tatarskaya arkheologiya, no. 3-4 (18-19), pp. 28-137. (in Russian).

Rudenko K.A., 2011. The cities and villages of Bulgar ulus of the Golden Horde (characteristics of material culture). Tatarskaya arkheologiya, no. 1-2 (20-21), pp. 32-151. (in Russian).

Savchenkova L.L., 1996. Ferrous metal of Bolgar. Typology. Gorod Bolgar: Remeslo metallurgov, kuznetsov, liteyshchikov. Kazan, Tatpoligraf Publ., pp. 5-88. (in Russian).

Fyodorov-Davydov G.A., 1966. The nomads of Eastern Europe under the sway of the Golden Horde khans. Archaeological monuments. Moscow, Publishing house of Moscow University. 274 p. (in Russian).

Fyodorov-Davydov G.A., 2001. The Golden Horde cities of the Volga region: Pottery. Trade. Way of life. Moscow, Publishing house of Moscow University. 256 p. (in Russian).

Khlebnikova T.A., 1988. Unglazed pottery of Bolgar. Gorod Bolgar: Ocherki remeslennoy deyatel'nosti. Moscow, Nauka Publ., pp. 7-102. (in Russian).

Fyodorov-Davydov G.A., 1984. The Culture of the Golden Horde Cities. Translated from the Russian by H.Bartlett Wells / BAR. International Series, 198. Oxford. 278 p.

Nedashkovsky L.F., 2004. Ukek: The Golden Horde city and its periphery / BAR. International Series. 1222. Oxford, Archaeopress Publ. 253 p. 


\section{Information about the Authors}

Leonard F. Nedashkovsky, Doctor of Sciences (History), Professor, Department of History of Tatarstan, Archaeology and Ethnology, Kazan (Volga region) Federal University, Kremlevskaya St., 18, 420008 Kazan, Russian Federation, Leonard.Nedashkovsky@kpfu.ru.

Marat B. Shigapov, Researcher, Institute of Archaeology named after A.Kh. Khalikov, Academy of Sciences of the Republic of Tatarstan, Butlerova St., 30, 420012 Kazan, Russian Federation, maratshigapov@gmail.com.

\section{Информация об авторах}

Леонард Федорович Недашковский, доктор исторических наук, профессор кафедры истории Татарстана, археологии и этнологии, Казанский (Приволжский) федеральный университет, ул. Кремлевская, 18, 420008 г. Казань, Российская Федерация, Leonard.Nedashkovsky@kpfu.ru.

Марат Баязитович Шигапов, научный сотрудник, Институт археологии им. А.Х. Халикова Академии наук Республики Татарстан, ул. Бутлерова, 30, 420012 г. Казань, Российская Федерация, maratshigapov@gmail.com. 